\title{
ESKI TÜRK ŞEHIRLERI VE SEMERKANT
}

\section{Dr. Cengiz ALYILMAZ*}

\section{ÖZET}

Hem Köktürk ve Uygur dönemi bengü taşlarında, hem de diğer eski Turk dili yadigârlarında bazen "balık (balgat / balgas / balgasun)", bazen "kent (çent / kant / kan / ken)", bazen "uluş", bazen de "il" kavram işaretiyle karşılanan ve geniş alanlar üzerine son derece sistemli bir şekilde inşa edilmiş olan Türk şehirleri, yerleşik Türk kultur ve medeniyetine tanıklık etmekte ve eski Türk yaşayış ve inanışından derin izler taşımaktadır.

Sőz konusu eski Türk şehirlerinin bir kısmı bizzat Tükler tarafından inşa edilmiş; bir kısmı ise, verilen mücadeleler, uzun yıllar devam eden savaşlar sonrasında Türk milletinin eline geçmiştir. Coğrafi konumları, zengin doğal kaynakları yưzünden tarih boyunca birçok milletin (dogal olarak da Türk milletinin) sahip olmak için ugraş̧ığı, uğruna canlar feda ettiği tarihî şehirlerden biri de Semerkant olmuştur.

erli ve yabancı kaynaklarda Türk milletinin tarihinden, geçmişinden soz edildiginde genelde "Türkler'in atlı ve göçebe kavim olduklan, geçimlerini hayvancılıkla temin ettikleri, avcı ve savaşçı bir ruha sahip oldukları" uzerinde durulur.

Tarihte kurulan birçok Türk devletinin külturel mirasını üzerinde barındıran Moğolistan Halk Cumhuriyeti'nde yapmış olduğumuz arașturma ve incelemelerde eski Türk kuiltür ve medeniyetine ait pek çok anıtın, yazıtın, heykelin, balbalın... yanında (adları yazıtlarda da geçen) çoğu Koktulrk ve Uygur dőnemlerine ait şehir kalıntılarının da bulunduğunu tespit ettik. Bu şehirlere ait kalıntıların büyulk bir bölümu, aradan bin yılı aşkm bir süre geçmesine rağmen hâlâ ayaktadır.

Eski Turk yazıtlannda ve eski Türk dili yadigârlarında bazen "balık (balgat / balgas / balgasun)", bazen "kent (çent / kant / kan / ken)", bazen "uluş", bazen de "il" kavram işaretiyle karşılanan ve geniş alanlar uzerine son derece sistemli bir

\footnotetext{
* Ataturrk Üniversitesi K. Karabekir Eggitim Fakultesi Türkçe Eğitimi Bölümũ Ögretim Üyesi.
} 
şekilde inşa edilmiş olan bu şehirler, yerleşik Türk kulltur ve medeniyetine tanıklık etmekte ve eski Türk yaşayış ve inanışından derin izler taşımaktadır. Türk kültur ve medeniyetinin bu eski ve köklü tanıklarına ait ayrıntılar ise (kaganlık sarayı, surlar, gozetleme kuleleri, bina kalıntıları, mezarlar, yazıtlar, dikili taşlar, sutunlar, sutun altlıkları, heykeller, dőşemeler, tuğlalar, künkler, kiremitler, sulama kanallan, metal, taş, ahşap ve seramik kullanım eşyalan) ${ }^{1}$ insanı ister istemez "Bunların oncesinde ve sonrasında da şehirler olmalı" düşlincesine sevk etmektedir. Nitekim Çinli rahip, seyyah Hsuaan Tsang'ın seyahatnamesinde bu duş̧unceyi haklı çıkaracak kıymetli bilgiler mevcuttur. Çin'in Kansu eyaletinden Hindistan'ı ziyaret etmek uzere yola çıkan ve 629 yılında Doğu Türkistan'a gelen Hstuan Tsang, buradaki şehirler (bugünkü Kumul, Koço (Kara Hoca), Karaşar, Kuça, Aksu) hakkında bilgi verir. Hsüan Tsang, daha sonra (630 yilında) önce Isıg Gơl'in batısinda Sûyâb şehrine sonra da Talas'a, Taşkent'e, Semerkant'a ve Buhara'ya... vd. uğrar. Hsüan Tsang, seyahatnamesinde bu şehirlerin oldukça geniş araziler uzerine kurulu olduklarını ve "şehir beyleri / reisleri" tarafindan idare edildiklerini kaydeder ${ }^{2}$.

Tarihte Türkler'in doğuda ve batıda yoğun olarak yaşadıkları, uğruna savaş verdikleri (Moğol istilasına kadar da birçoğu devrinin en işlek merkezlerinden olan) bazı şehirler şunlardır:

Beş Bahık, Togu Balık, Bavıl Balık, Bay Balık, Ordu Balık (Kaşgar, Kaş Balık, Ka-Şa, Sulek / Sule ), Kuz Balık (Gu Balık, Kuz Ordu, Kuz Uluş, Ordu Kent, Balagasun), Can Balık, Çakuk Balık, Yengi Balık, Barçınlıg Kent, Man Kent, Öz Kent (Öz Çent, Fergana), Taş Kent (Çaç, Şaş, Terken), Tün Kent, Serniz Kent (Semerkant), Süt Kent, Yar Kent, Yegen Kent, Temir Kapıg (Temir Kapl, Demirkapı), Turfan, Bukarak (Buhara), Suğnak (Sıgnak), Karnak, Barçuk, Karaçuk, Kazvin, Kinküt, Koçungar Başı (Koçgar Başı, Koç Başı), Kuça, Argu (Argu), Aşnas, Sayram (İsbicab), Savran, Talas (Taraz, Kumi Talas, Ulug Talas), Sûyâb, Cend, Yafinç, Yafgu, Almalıg, Altun Kır, Altındag, Altun Tepe, Çuy Tepe, Turtkul Tepe, Çardarı, Bayırkum, Balu, Barsgan, Barhan, İşkan, Kençek Sengir, Yesî,

1 Konuyla ilgili ayrıntılı bilgi için bk: Alyılmaz, Cengiz, Moğolistandaki Türk Anıtları Projesi 2000 Yılı Çalışmaları Işı̆̆ında Bazı Tespitler, Gơktürk Devleti'nin 1450. Kuruluş Yildönümü Sempozyum Bildirileri, Ankara, 2001, s. 67-75; Balınt, Csanat, VI.-VIII. Yúzyllarda İç Asya ve Orta Asya'daki Türk Tipi Arkeoloji Anıtlan, Türk Kültürd Araştırmaları Dr. Emel Esin'e Armağan, XXIV / 1, Ankara, 1986, s. 7-32; Baykara, Tuncer, Türklügün En Eski Zamanları, Türkler Ansiklopedisi, C. I, Ankara, 2002, s. 277 306; Daşnyam, Luvsandambın (vd), Mongol Nutag Dah' Tuuh Soyalın Dursgal, Ulaanbaatar, 1999; Esin, Emel, İç Asyada Milattan Önceki Bin Yılda Tüklerin Atalarına Atfedilen Kültürler, Türkler Ansiklopedisi, C. I, Ankara, 2002, s. 494-517; Sertkaya, O. F., - Alyılmaz, C. - Battulga, Ts., Mogolistandaki Türk Anıtları Projesi Albumti, Ankara, 2001.

2 Sümer, Faruk, Eski Turklerde Şehircilik, Ankara, 1994, s. 11-19. 
Ribâtât....vd ${ }^{3}$. Kimi tarihî "kale şehir", kimi de daimî yerleşim alanı / merkezi durumundaki bu şehirlerin birçoğunun adı, hem Köktük ve Uygur dơnemi bengü taşlarında, hem de diğer eski Türk dili yadigârlarında (başta Dîvânü Lûgati't-Türk olmak uzere) geçmektedir.

Örnekler:

otuz yaşıma beş balık tapa süledim altı yolı süngüş̧üm: Otuz yaşımda Beşbalık'a (Beşşehir'e) doğru asker sevk ettim; altı kez savaştım.

\section{Bilge Kağan Yazıtı D 28}

en ilki togu balıkda süngüşdimiz: İlk önce Togu şehrinde savaştık.

\section{Köl Tigin Yazıtı K 4}

sogdak tabgacka selengede bay balık yapıtt birdim: Soğdlar'a ve Çinliler'e Selenga (ırmağı yakınlarında) Baybalık (Bay şehrini) yaptırdım.

\section{Moyunçur / Bayan Çor Yazıtı 44}

koçu balıkda kelmiş kılıç kliç karaka yarlıg boltı: Koçu şehrinden gelmiş olan kılı̧ Küç Kara'ya iletildi.

\section{Miran Kalesi El Yazmaları I/ A 11-12}

... kutlug uluş yaraşhg altun arugu uluş kaşu yegen kent ordu kent çigil balık ...: Kutlu, mükemmel Altun Argu șehri, Kaşu (şehri), Yarkent Yar (şehri), Ordukent (Ordu şehri / Kaşgar) ve Çiğil şehri ...

\section{Türkçe Mânî El Yazmalanı (Manichai) I}

3 Eski Türk şehirleri hakkında ayrıntılı bilgi için bk.: Arat, R. Rahmeti, Kâşgar, İslâm Ansiklopedisi, C. 6, İstanbul, 1955, s. 405-412; Barthold, V. V. Moğol İstilâsına Kadar Türkistan, Ankara, 1990, (Haz. Hakkı D. Yıldız); Esin, Emel, İslâmiyetten Önceki Türk Kültür Tarihi ve İslâma Giriş, Istanbul, 1978; Esin, Emel, Balık and Ordu, Central Asiatic Journal- XXVII / 3-4, Wiesbaden, 1983, s. 169-208; Emel, Esin, Turk Minaresinin Orta Asyadaki Önculeri Hakkında, Ataturk Üniversitesi Edebiyat Fakültesi Araştırma Dergisi, Sayı:9, Ankara, 178, s. 103-147; Genç, Reşat, Kaşgarlı Mahmud'a Gorre XI. Yüzyılda Türk Dunyası, Ankara, 1997; Kafesoğlu, İbrahim, Türk Millî Kültüru, İstanbul, 1993, s. 309-312; Ligeti, L., Bilinmeyen lł Asya, Ankara, 1986, (Çev. Sadrettin Karatay); Mahpirov, V. U., Imena Dalekih Predkov, Almatı, 1997, s. 239-266; Ögel, Bahaeddin, Türk Kültür Tarihine Giriş, C. I, Ankara, 1991, s. 143-303; Roux, Jean-Paul, Orta Asya Tarih ve Uygarlık, İstanbul, 2001, (Çev. Lale Arslan); Sayan, Yüksel, Turkmenistan'daki Mimarî Eserler (XI-XVI. Yüzyıl), Ankara, 1998; Şeşen, Ramazan, Islâm Coğrafyacılarına Göre Türkler ve Türk Ullkeleri, Ankara, 1998; Togan, Zeki Velidî, Balasagun, İslâm Ansiklopedisi, C. 2, İstanbul, 1961, s. 269-272. 
bu kitabnı tasnif kılıglı balasagun mevludlug perhiz idisi er turur: Bu kitabı yazan Balasagun şehrinden takvâ bir zattır.

\section{Kutadgu Bilig A 23-24}

barusın bitimiş yeturmiş nizam / bu kaşgar ilinde koşulmış temam; Esasını yazmış ve tertip etmiş; fakat bu (manzume) son şeklini Kaşgar ilinde almıştır.

\section{Kutadgu Bilig B 59}

kend: Şehir. Bu kelimeden alınarak Kaşgar için "Ordu Kend" derler. Hanın oturduğu şehir demektir. Çükü Afrasyap, havası güzel olduğu için burada otururdu.

\section{Dîvânü Lûgatił-Türk I, 343.}

Kençek Sengir: Talas yakınında bir şehrin adıdır. Burası Kıpçak sınırıdır.

Dîvânù Lûgati't-Türk I, 480.

sugnak: Oguz şehirlerinden biri

Dîvânü Lûgati't-Türk 1,471 .

karnak: Oğuz şehirlerinden biri

Dîvânú Lûgatitt-Türk I, 473.

kend: Oğuzlar'la Oğuzlar'a uyanlara göre kőy; Türkler'in büyük bir kısmına göre "şehir" demektir. Bundan alınarak Fergana'ya "Öz Kent" adı verilmiştir; "Kendimizin Şehri" demektir. Yine bőylece "Semiz Kent" denir; büyük olduğundan bőyle denilmiştir. Farsça'da "Semer Kand" denir.

Dîvânü Lûgati't-Türk I, 344.

Eski Türk şehirleri hakkında Ebu'l Kasım Ubeydullâh b. Hurdâdbih tarafindan yazılıp 886 yılında tamamlanan Kitâbü'l - Mesâlik ve'l - Memâlik"te; 981 984 yılları arasında Kao-ch'ang Uygurları'na elçi olarak giden Wang Yen-t'ê'nin seyahatnamesi'nde; 982 yılında yazılmış olan "Hudûdu'l - Âlem"de; 1040'lı yıllarda Ebû Sa'id Abdalhayy b. Dahhâk el-Gerdîzî tarafından yazılmı̣ Zeynü'l-Ahbâr'da; 1154 yılında Ebû Abdullâh b. Muhammed el - Şerîf el İdrisî tarafindan yazılmış "Nüzhetư'l - Müşâk'ta; XII. yüzyılda Alaaddin Ata Melik Cưveynî tarafindan yazılmış "Tarih-i Cihangüșa"da da önemli bilgiler mevcuttur. Bütun bu kaynaklardaki bilgiler, birçok boya, ele, obaya ayrılan Türkler'in tarihin en eski donemlerinden beri bir kısmının şehirlerde; bir kısmının ise, koylerde ve bozkırlarda yaşadıklarını ortaya koyar niteliktedir 4 .

4 Ayruntılı bilgi için bk.: İzgi, Őzkan, Çin Elçisi Wang Yen Te'nin Uygur Seyahatnamesi, Ankara, 1989; Ögel, Bahaeddin, Türk Kültür Tarihine Giriş, C. I, Ankara, 1991, s. 143- 
Haklarında hem eski Tük dili yadigârlarında hem de en ciddî tarihî kaynaklarda (tarih ve cografya kitaplanında, seyahatnamelerde) bilgiler bulunan eski Türk şehirlerinin bir kısmı bizzat Türkler tarafından inşa edilmiş; bir kısmı ise, verilen mücadeleler, uzun yıllar devam eden savaşlar sonrasında Türk milletinin eline geçmiştir. Coğrafi konumları, zengin dogal kaynakları yüzünden tarih boyunca birçok milletin (doğal olarak da Türk milletinin) sahip olmak için uğraştığı, uğruna canlar feda ettigi tarihî şehirlerden biri de Semerkant'tır.

Buglin Özbekistan Cumhuriyeti sınırlanı içinde kalan ve Eski Türk dili kaynaklarında adı "Semiz Kent" olarak geçen Semerkant'ın tarihi hakkında farklı görüşler mevcuttur. Ancak konuyla ilgli araşturmacıların çoğu, buranın (Marakanda'nın / Ulu SSehir'in) M.Ö. Soğdlar'ın başkenti oldugunu; Aleksandr İskender (Büyük İskender) tarafindan M.Ö. 329 yllında ele geçirildiğini; 712 yılında Araplar tarafindan (Kuteybe b. Müslim tarafindan) fethedildiğini; IX-X. yuizyıllarda Samanîler yönetiminde parlak bir dönem yaşadığını; XI. yulzyılda Karahanlılar'ın; 1089-1130 yılları arasında Selçuklular'in, XII. yüzyılda Karahıtaylar'ın ve Harzemşahlar'ın egemenliģi altına girdigini kaydetmektedirler. Salnamelerden ve tarihî kaynaklardan edinilen bilgilere göre Semerkant, yöneticilerinin teslim olmamaları yuzuinden 1220 yılında Cengiz Han tarafindan yakıllp yıkılır. Sehir, sonraki yıllarda Timur'un burayı âdeta yeniden inşası ve başkent yapmasıyla tekrar canlanır; döneminde dünyanın en gözde ilim, sanat ve edebiyat merkezi hâline gelir. Bu yıllarda șehir, hem Turkistan Türkleri'nin hem de bilim ve sanat erbabının buluşma noktası olur. Devlet adamları ve devrin ileri gelenleri yaptırdıkları ilim, sanat ve mimarî eserleriyle şehre Türk-ìslâm külttir ve medeniyetinin damgasını vururlar. Timur'un olümunden sonraki (1405'ten sonraki) yillarda da Semerkant, özellikle Muînu'd-dîn Şahruh Mirza'nun oğlu Muhammed Taragay Uluğ Bey'in hâkimiyetinde (1394-1449) aynı canlılığını korur ${ }^{5}$. Şehirde yeni saraylar, hanlar, medreseler ve bir de rasathane inşa edilir. Uluğ Bey'in yaptırdığı ve bizzat kendisi ve öğrencileri tarafindan bilimsel çalıșmaların gerçekleştirildiği rasathanenin ve medresenin / akademinin unü (dolayısıyla da Semerkant'in unü), kıtalar ötesine ulaşır. Ancak sonraki yıllarda şehir birçok savaşa sahne olur; 1496 yılında Zahirú'ddîn Muhammed Babur (1483-1530) ; 1501 yllında ise, Muhammed Şeybani Han (ölm. 1510) tarafindan ele geçirilir. Şehri ele geçirmek için yapılan savaşlarda birçok tarihî eser (saray, medrese, cami, türbe) zarar görür. XVI. yüzyılın başlarında bölgenin yönetimini ellerinde bulunduranlar, başkenti Semerkant'tan Buhara'ya taşırlar. Buna rağmen, șehir, Hindistan-Turkistan ve Iran ticaret yolu (İpek Yolu) kavşağında bulunduğundan her zaman ilgi merkezi olmaya devam eder. Semerkant,

303; Sümer, Faruk, a.g.e., s. 11-19; Şeşen, Ramazan, İslâm Coğrafyacılanna Gơre Türkler ve Türk Ülkeleri, Ankara, 1998.

5 Konuyla ilgili olarak bk.: Aka, Ismail, Timur ve Devleti, Ankara, 1991; Askarov, Ahmedali, Temur ve Ulugbek Devri Tarihi, Taskent, 1996. 
1868 y1lında Ruslar tarafindan Türkistan Genel Yönetim Bölgesi'ne katılır; 19241930 yılları arasında da Özbekistan Sovyet Sosyalist Cumhuriyeti'nin başkenti olur ${ }^{6}$.

Stratejik konumu, yer altı ve yer üstl zenginlikleri bakımından tarihin her döneminde birçok milletin dikkatini üzerine çeken, uğnuna savaşlar verilen Semerkant, bugün sınırlan içinde birbirinden farklı kultürlerin mirasını barındırmaktadır. Sőz konusu bu kultürel mirasın oluşmasında Türkler'in (סzellikle de Timur ve onun soyundan gelenlerin) rolu büyüktür.

Bugün Semerkant'ta bulunan kültür ve medeniyet eserlerinin en onemlileri şunlardır: ${ }^{7}$

1- Afrasyab şehrinin kalıntıları

2- Ruhabad

3- Gur Emir (Emir Timur Türbesi / Emir Timur Aile Mezarlığı)

4- İşrethane

5- Abdi Derun

6- Çolpan Ata Türbesi

7- Uluğ Bey Rasathanesi

8- Registan

8.1. Ulug Bey Medresesi

8.1. Şir Dâr Medresesi

${ }^{6}$ Semerkant'ın tarihi , bir Türk şehrine dönüştürulmesi ve bugünku görünumuünü alması hakkında ayrıntılı bilgi için bk.: Ahun-Babaev, H. G., Dvorets İhşidov Sogda na Afrasiabe, Semerkant, 1999; Bababekov, H. (vd), Özbekistan Tarihi, Taşkent, 2000; Barthold, V. V. a.g.e., s. 88-105; Büyük Larousse Sözlük ve Ansiklopedisi, C. 20, İstanbul, 1986, s. 10346; Feyziev, Turgun, Temurîyler Seceresi, Taşkent, 1995; Kahhar, Tahir, Hür Türkistan Üçün, Taşkent, 1994; Kitap̧̧ı, Zekeriya, Orta Asya Türklüğunün Büyük İslâm Kültür ve Medeniyetindeki Yeri, Konya, 1995, s. 61-65; Nẻbiev, Abdurahman, Müstekillik Üçün Küreş Yahud Parçalangan Türkistan Tarihi, Taşkent, 1998; Şeşen, Ramazan, a.g.e., s. 226-233; Tühliev, Nurislam (vd.), Özbekistan Vilayetler ve Karakalpakistan, Taşkent, 1995.

7 Semerkant'taki tarihî eserler hakkında ayrıntılı bilgi için bk.: Abdurahmanov, A., Uluğbek Akademiyası, Taşkent, 1993; Aslanapa, Oktay, Türk Cumhuriyetleri Mimarlık Abideleri, Ankara, 1996; Berdimmuradov, Emriddin, Guri Emir Mekberesi, Taşkent, 1996; Pugaçenkova, G. A., Temurning Me'mariy Merasi, Taşkent, 1996; Ramazanoglu, Gözde, Orta Asyada Türk Mimarisi, Ankara, 1998, s. 83-176; Şaymerdanov, I. (VD), Emir Temur Cehan Tarihide, Taşkent, 1996; Tühliev, Nurislam (vd.), a.g.e., s. 58-66. 


\subsection{Tillâkârî}

9- Nadir Divan Beyi Medresesi

10- Hoca Ahrar Külliyesi

11- Bibi Hanım Külliyesi

12- Bibi Hanım Türbesi

13- Şah-1 Zinde

13.1. Kadızade Rumî Türbesi

13.2. Emirzade Rumî Türbesi

\subsection{Türkân Aka Türbesi}

13.4. Emir Burunduk Türbesi

13.5. Tuman Aka Türbesi

13.6. Hoca Ahmet Türbesi

13.7. Kusem İbn Abbas Turbesi

13.8. Vasmıgrannik Türbesi

13.9. Sirin Bike Ata Turbesi

13.10. Kusem İbn Abbas Türbesi

13.11. Tuğlu Tekin (Emir Hüseyin) Türbesi

14- İsmail Buharî Külliyesi

15- İmam Matrudi Turbesi

16- Danyal Peygamber'in Kabri

Türk hükumdarları, hanları, devlet adamları ve ileri gelenleri tarafindan yaptırılan bu eserler sayesinde Semerkant'ın çehresi değişmiş; şehir, âdeta Türkİslâm külttur ve medeniyetinin en önemli merkezlerinden biri hâline gelmiştir. 


\section{BİBLIYYGRAFYA*}

BAYKARA, Tuncer, Türk Şehircilik Tarihinden: Hatun Şehirleri, TTK Belleten, C. XLIV, Ankara, 1980, s. 497-510

BAYKARA, Tuncer, Türk Tarihi ve Şehir: Türklerde Yerleşik Hayat, Yeni Turkiye, Sayı: 45, Ankara, 2002, s. 421-438. ULUĞTÜRK).

EBERHARD, W., Çin'in Şimal Komşuları, Ankara, 1996, (Çev. Nimet

DIVİTÇİOĞLU, Sencer, Oguz'dan Selçuklu'ya Boy, Konat ve Devlet, İstanbul, 2000.

DONUK, Abdülkadir, Balık, İslâm Ansiklopedisi, C. 5, İstanbul, 1992, s. 12.

GABAIN, A. v., Kőktürklerin Tarihine Bir Bakış III Şehir Gơzüyle Step, A.Ü. DTCF Dergisi, C. VIII, Sayı: 3, Ankara, 1950 , s. 373-379, (Çev. S. ÇAĞATAY)

GÖKER, Lutfi, Uluğ Bey Rasathanesi ve Medresesi, İstanbul, 1995.

GUMiLYEV, L. N., Eski Türkler, İstanbul, 1999., (Çev. Ahsen BATUR).

HASSAN, Ümit, Eski Turk Toplumu Üzerine İncelemeler, Ankara, 1986.

HAUSSIG, Hans Wilhelm, İpek yolu ve Orta Asya Kültür Tarihi, Kayseri, 1997, (Çev. Müjdat KAYAYERLì).

ÖGEL, Bahaeddin, İslâmiyetten Önce Tưrk Tarihi Orta Asya Kaynak ve Buluntularına Göre, Ankara, 1988.

PUGAÇENKOVA, Galina A., Şedevrı Sredney Azii, Taşkent, 1986.

PUGAÇENKOVA, G. A.- REMPEL', L. İ., Oçerki İskusstva Sredney Azii, Moskova, 1982.

RAŞONYI, Laszlo, Tarihte Türklük, Ankara, 1988.

RTVELADZE, Edvard, Velikiy Şelkoviy Put', Taşkent, 1999.

SAFRAN, Mustafa, Yaşadıkları Sahalarda Yazılan Lûgâtlara Göre Kuman / Kıpçaklar'da Siyasî, İktisadî, Sosyal ve Kưltürel Yaşayış, Ankara, 1993.

SARAY, Mehmet, Dogu Türkistan Türkleri Tarihi (Başlangıçtan 1878'e Kadar), C. I, İstanbul, 1998.

\footnotetext{
* Bibliyografyaya dipnotlarda gősterilen eserler dahil edilmemiştir (C.A.).
} 
SEÇGIN, Nuri, Anadolu Türk Şehirciliǧi, Yeni Türkiye, Sayı: 45, Ankara, 2002, s, 439-448.

SHNOR, Denis, Erken Iç Asya Tarihi, İstanbul, 2000.

SÜLEYMANOV, R. H., Drevniy Nahşab, Semerkant-Taşkent, 2000.

SÜMER, Faruk, Oğuzlar (Turkmenler) Tarihleri - Boy Teşkilatı Destanlar, İstanbul, 1992.

TAŞAĞIL, Ahmet, Goktürkler, C. I, Ankara, 1995; C. II, Ankara, 1999.

TEKIN, Şinasi, Metinlere Dayanarak Eski Türklerde Göçebe (Ötưken) ve Şehir (Hoçu) Medeniyetlerinin Tahlili, Atatük Üni. Edebiyat Fakultesi Araştırma Dergisi, Sayı: 3, Erzurum, 1972, s. 35-60.

TEKIN, Talat, Orhon Yazitları, Ankara, 1988.

VOYTOV, V., Drevnetyurkskiy Panteon i Model' Mirozdaniya, Moskova, 1996.

\begin{abstract}
Turkish cities which were contrusted on large areas systematically and were named as "il" or "uluş", "balık (balgat / balgas / balgasun), "kent (çent / kant / kan / ken)" in both eternal stones belonging to Kokturk and Uygur ages, and other old Turkish language publications demonstrate Turkish culture and Turkish civilizetion.

Some of these cities were constructed by Turkish and some were captured in the result of challenge and wars taking long years. Among these historical cities, one which a lot of nations struggled and lost many people to capture is Semerkant.
\end{abstract}


